\title{
COMPLICATED AMYAND'S HERNIA IN A NEONATE MIMICKING INGUINAL ABSCESS
}

\section{Bashir Ur Rahman $^{\otimes 1}$, Asma Bibi ${ }^{2}$, Shahbaz Zafar ${ }^{3}$, Asma Yaqoob ${ }^{4}$}

\begin{abstract}
Amyand's hernia is a rare form of hernia in which the vermiform appendix is present within the inguinal hernia sac. Here, we report a 12 days-old neonate with features of inguinal abscess referred to us with a tender irreducible right inguino-scrotal swelling. On examination, there was tender swelling right inguino-scrotal region with abdominal wall edema extending up to right lower quadrant. Surgical exploration showed long appendix with a gangrenous I/3 of distal appendix, periappendicular abscess in the inguinal hernia sac. Appendectomy and right herniotomy was performed. Amyand's hernia presentation is variable: from a reducible inguinal hernia containing a normal appendix, to acute abdomen due to perforation of acute appendicitis secondary to incarceration. Only imaging can verify the contents of an incarcerated inguinal hernia. Surgical approach varies depending upon findings. In our case, we used separate incision for appendectomy because of a very long appendix and high lying caecum in right hypochondrium with difficulty to bring base of appendix down for ligation.
\end{abstract}

KEY WORDS: Hernia (MeSH); Amyand's Hernia (Non-MeSH); Inguinal Abscess (Non-MeSH); Gangrenous Appendicitis (Non-MeSH); Abdominal Wall Edema (Non-MeSH).

THIS ARTICLE MAY BE CITED AS: Rahman BU, Bibi A, Zafar S, Yaqoob A. Complicated Amyand's hernia in a neonate mimicking inguinal abscess. Khyber Med Univ J 2019; I I(2): I02-3. DOI:I0.35845/kmuj.2019.17328

\section{INTRODUCTION}

A myand's hernia is rare with a reported incidence of $0.07-0.08 \%$ of all cases of inguinal hernia. ${ }^{1-3}$ Presence of gangrenous appendix with periappendicular abscess mimicking an inguinal abscess is rare. The presentation of Amyand's hernia is similar to that of any inguinal hernia, with additional features of red, tender and irreducible swelling if contents are incarcerated. When it contains inflamed appendix, it can mimic testicular inflammation, torsion or an abscess. It is difficult to judge and make a proper diagnosis before surgery until explored. We hereby report a case of complicated Amyand's hernia in a neonate who presented with a tender right inguino-scrotal swelling. Surgical exploration showed gangrenous appendix with a peri-appendicular abscess in the inguinal hernia sac.

\section{CASE REPORT}

A 12 days old term baby referred to us from local clinic with complaint of excessive crying, vomiting, and swelling right side inguino-scrotal area since 5 days. Baby was irritable for the last 3 days. Baby was passing stool and his chest was clear. On examination, his temperature was $102^{\circ} \mathrm{F}$ and there was a red, hot and tender swelling at right inguinal area. There was abdominal wall erythema and edema up to umbilicus and mild swelling at right side scrotum mimicking an inguinal abscess. Left scrotum was normal with testis palpable in sac. His leukocyte count was $29000 / \mathrm{mm}^{3}$ and C- reactive protein was positive. Ultrasonography findings included collection at right side scrotum and inguinal canal with suspicion of gut and right testis inflamed with scrotal thickness. After resuscitating the baby and lowering his temperature, emergency surgical exploration was made. Through right inguinal incision muscles incised and inguinal canal approached. Gangrenous tortuous appendix with peri-appendicular abscess and marked edema of the spermatic cord was found in inguinal canal so herniotomy performed. However, due to edema there was difficulty to identify and dissect the contents of spermatic cord. Since the appendix was very long and the cecum was high, so second
I. Assistant Professor, Department of Pediatrics Surgery Rawal Institute of Health Sciences Islamabad, Pakistan.

Email $\otimes$ : drbashir_khali@@yahoo.com

Contact \#: $\quad$ +923341054806

2. Senior Registrar, Department of Surgery Fauji Foundation Hospital Rawalpindi, Pakistan

3. Senior Registrar, Department of Surgery Rawal Institute of Health Sciences Islamabad, Pakistan.

4. Associate Professor, Department of Pediatrics Medicine, Rawal Institute of Health Sciences Islamabad, Pakistan

$\begin{array}{ll}\text { Date Submitted: } & \text { January I, } 2019 \\ \text { Date Revised: } & \text { May 23, 2019 } \\ \text { Date Accepted: } & \text { May 24, 2019 }\end{array}$

incision was made in right iliac fossa for appendectomy. Inguino-scrotal cavity was washed with normal saline and all layers were closed separately with vicryl $4 / 0$. Intravenous (IV) Cefotaxime $100 \mathrm{mg} / \mathrm{kg}$ was given for two days and patient discharged on third post-operative day on oral Cefpodoxime $4 \mathrm{mg} / \mathrm{kg}$ dose in two divided doses for three days and was followed up on $6^{\text {th }}$ post-operative day. On follow up, the wound was healthy, edema subsided and baby was active.

\section{DISCUSSION}

When appendix is present in the hernia sac, it is termed Amyand's hernia; named after Claudius Amyand, surgeon of King George II, who described this first in I735.' Its presentation is atypical mimicking certain other diseases as inguinal abscess, testicular torsion, incarcerated hernia, epididymo-orchitis. There is redness inguinal area with scrotum and extends to abdominal wall when peri-appendicular abscess coexists. Tenderness is positive with patient having high-grade fever with excessive crying and vomiting

Amyand's hernia is common on right side due to anatomic location of appendix; however, left sided may be seen in situs inversus. When the appendix is retained within hernia sac adhesions may form and there might develop inflammation mimicking inguinal abscess or incarcerated hernia with bacterial translocation leading to sepsis. ${ }^{2}$ Later, obliterating endarteritis may lead to thrombosis, ischemia and gangrene as it occurred in our case.

It is difficult to diagnose Amyand's hernia preoperatively as symptoms are variable. 


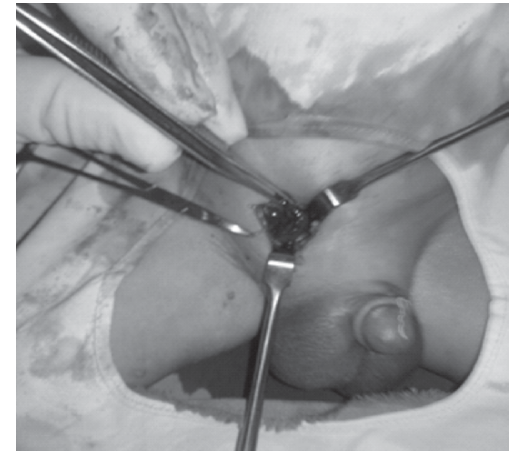

Figure I: Gangrenous tortuous appendix

Fever and leukocytosis may be present depending on presence of inflamed appendix or perforation with gangrene. ${ }^{3}$ However, ultrasound and CT scan may be helpful in diagnosis. ${ }^{4,5}$ CT scan may help in detecting situs inversus or other co-existing anomalies. Color doppler may be a useful modality in cases suspected of gangrene or inflammation with no or increased vascularity. ${ }^{6}$ Plain X-ray abdomen showing gas shadow in scrotum also done presuming hernia in a case report.

There is still no consensus in managing Amyand's hernia. Only herniotomy performed in cases with normal appendix. Appendectomy is done when inflamed or perforated appendix or in left sided Amyand's hernia regardless of condition of appendix with herniotomy. ' Laparoscopic approach is also in use for exploration. ${ }^{7.8} \mathrm{~A}$ high mortality about $13-40 \%$ is seen in perforated appendix and sepsis cases.

\section{CONCLUSION}

Amyand's hernia with appendicitis is very rare, more so in neonates. A high index of suspicion may help. Surgeons should keep

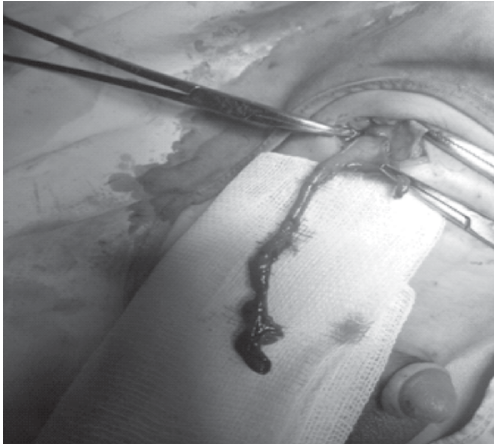

Figure 2: Appendix with black distal part

this rare condition in the list of differential diagnosis while evaluating children with irreducible inguino-scrotal swellings, and must be familiar with its management options for the optimal outcome. It is rare to find a gangrenous appendix within sac as in our case. Early diagnosis may prevent such complication.

\section{REFERENCES}

I. Mandhan P, Al Rayes T, J Ali M, Aldahaheri M. Complicated Amyand's hernia in a neonate. J Neonatal Surg 20|4;3(3):38.

2. Rajaguru K, Tan Ee Lee D. Amyand's hernia with appendicitis masquerading as Fournier's gangrene: $A$ case report and review of the literature. J Med Case Rep 2016;10(I):263. DOI: 10.1186/ sl3256-016-1046-9

3. Dange A, Gireboinwad S. A rare case of Amyand's hernia presenting in a 3-yearold male child. Indian J Surg 20 I $3 ; 75(4): 332-3$. DOI: 10.1007/s 12262-013-0870-z

4. Ngom G, Amadou I, Ibrahima KA,

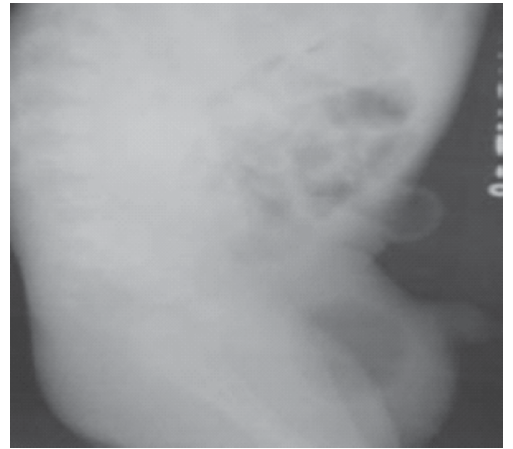

Figure 3: Plain $X$ - ray showing gas shadow scrotum

Mubake A, Ndour O, Ndoye M. Rare disease. Amyand's hernia with perforated appendix in a neonate. BMJ Case Rep 2010; 2010:bcr 0320102847. DOI: 10.1 136/ bcr.03. 2010.2847

5. Yoneyama F, Tanaka H, Ono K, Sasaki T, Jimbo T, Gotoh C, et al. An incarcerated appendix and the ileocecum within a left inguinal hernia in an infant. Surg Case Rep 2015; I (I):6I. DOI: 10.1 I86/ s40792-015-0064-y

6. Vehbi H, Agirgun C, Agirgun F, Dogan Y. Preoperative diagnosis of Amyand's hernia by ultrasound and computed tomography. Turk J Emerg Med $2016 ; 16(2): 72-4$. DOI: I0.1016/j.tjem.2015.11.014

7. Khatoon R, Khan YA, Saddal NS. Perforated appendicitis with periappendicular abscess in an Amyand's Hernia. APSP J Case Rep 20 13;4(3):37.

8. Al Maksoud AM, Ahmed AS. Left Amyand's hernia: An unexpected finding during inguinal hernia surgery. Int J Surg Case Rep 2015; | 4:7-9. DOI: I0.1016/j.ijscr.2015.06.029

\section{AUTHORS' CONTRIBUTIONS}

Following authors have made substantial contributions to the manuscript as under:

BUR \& AY: Identification \& diagnoses of the case, management of the case, final approval of the version to be published

AB \& SZ: Manuscript witting, final approval of the version to be published

Authors agree to be accountable for all aspects of the work in ensuring that questions related to the accuracy or integrity of any part of the work are appropriately investigated and resolved.

CONFLICT OF INTEREST
Authors declared no conflict of interest
GRANT SUPPORT AND FINANCIAL DISCLOSURE
NIL

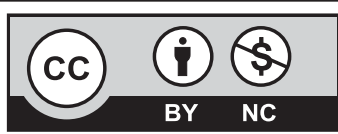

This is an Open Access article distributed under the terms of the Creative Commons Attribution-Non Commercial 2.0 Generic License. 